\title{
Little change in inter-canine width during orthodontic treatment
}

\author{
Burke S P, Silveira AM, Goldsmith LJ, YanceyJ M. A meta-analysis of mandibularinter-canine width in treatment \\ and post-retention. Angle Orthod 1998; 68:53-60
}

Objective To identify and compare studies quantifying intercanine width pre- and post-treatment and to propose a baseline for canine adjustment.

Data sources A search of Medline and unpublished master's thesis and references cited in located articles. Hand searching of recent issues of relevant journals was also carried out. Authors were contacted for access to mean or primary data.

Study selection Studies were included if numerical data was available to show changes in inter-canine width from pre to post treatment and post retention, if there was adequate information relating to the subjects, treatment retention devices and post retention records. When more than one study used the same patient records only the original paper was used. 26 studies met the criteria.

Data extraction and synthesis Data from 1233 patients was pooled to give an overall mean change in inter-canine width. Subgroup analysis was also performed based on Angles Incisor classification and extraction and non-extraction therapy.

Results The table shows the changes in inter-canine width in millimetres

\begin{tabular}{|c|c|c|c|c|}
\hline & $n$ & $\begin{array}{l}\text { Mean change } \\
\text { during } \\
\text { treatment }\end{array}$ & $\begin{array}{l}\text { Mean post } \\
\text { retention } \\
\text { treatment }\end{array}$ & $\begin{array}{l}\text { Mean } \\
\text { net } \\
\text { changes }\end{array}$ \\
\hline All patients & 1233 & 1.57 & -1.24 & $\begin{array}{c}0.33 \\
(0.23-0.43)\end{array}$ \\
\hline Non-extraction & 616 & 1.45 & -1.17 & $\begin{array}{c}0.28 \\
(0.14-0.41)\end{array}$ \\
\hline Extraction & 510 & 1.78 & -1.41 & $\begin{array}{c}0.39 \\
(0.26-0.55)\end{array}$ \\
\hline
\end{tabular}

Conclusions Mandibular inter-canine width tends to expand during treatment by $0.8-2.0 \mathrm{~mm}$, and constrict post-retention by 1.2-1.9 mm regardless of pre-treatment classification or whether treatment was extraction or non-extraction. Post-retention mandibular inter-canine widthshows a net change from $0.5 \mathrm{~mm}$ expansion to $0.6 \mathrm{~mm}$ constriction. Since the net change is approximately zero this study supports the concept of maintenance of original inter-canine width in orthodontic treatment.

\section{Address Dr Anibal M Silvera, University of Louisville School of Dentistry, 501 South Preston Street, Louisville, Kentucky 40292, USA}

\section{Commentary}

This paper seeks to combine the results of studies related to changes in mandibular inter-canine width through treatment and retention. This important topic in orthodontics addresses the controversial issue of whether expansion or extraction therapy in the lower arch provides the more stable result.

All of the studies in this article followed patients from the beginning of treatment to the end of retention. The authors made a reasonable attempt to standardise the data sets as well as avoiding duplication of results using data from original papers where appropriate.

One of the weakest areas of this paper was that there was no documentation of the appraisal process for each study. It is evident that greater weight was given to studies with larger numbers rather than quality of study design but there was no detailed description of individual study methodologies. Although this is a multiauthor article, there was no assessment of inter-examiner variability in the appraisal of the studies. This lack of appraisal assessment would not permit easy reproduction of this study.

The results are certainly not similar from study to study either quantitatively or qualitatively. Some studies indicate contraction of the arch, others show expansion. It is therefore difficult to ascribe weighting as there are no details regarding the individual study design.

The effect size is quite small reflecting the relatively small amount of movement seen in orthodontic relapse. The results demonstrate a high statistical significance but this is not surprising as the study includes over 1200 patients. Thus, although statistical significance is high, clinical significance is low. This is difficult to assess, as there is no specific information on age, gender, social stratum or ethnic grouping. This information may not have been available but otherwise it is probable that the results are generally applicable, to other groups of patients in the USA and possibly in the UK.

Lateral expansion of the lower arch during orthodontic treatment is a contentious issue. This paper attempts to synthesise the available evidence on the stability of mandibular inter-canine width during and after treatment. The main conclusion of this study is that mandibular inter-canine width increases during treatment regardless of pretreatment incisor classification or whether the treatment was carried out on an extraction or non-extraction basis. This increase in width reduces again following retention resulting in a mean zero change in mandibular width over the observed period. The authors conclude that this study supports the concept of maintenance of original inter-canine width in orthodontic treatment. This supports the belief of many orthodontists that any lateral expansion of the lower arch is inherently unstable.
Julian R.S. O'Neill ${ }^{1}$ and Pippa Slade ${ }^{2}$ ${ }^{1}$ Consultant Orthodontist and ${ }^{2}$ Clinical Audit Facilitator, Kettering General Hos- pital, Kettering, UK 